\title{
Notas sobre a concepção hobbesiana das relações do desejo e da razão com o tempo
}

\author{
Notes on the Hobbes's conception of the relation between desire \\ and reason with time
}

\author{
João Carlos Brum Torres \\ brumtorres@gmail.com \\ (Universidade de Caxias do Sul e Universidade Federal do Rio Grande do \\ Sul, Rio Grande do Sul, Brasil)
}

\begin{abstract}
Resumo: 0 propósito deste artigo é discutir o modo como Hobbes concebe a relação do desejo com o tempo, entendido o ponto como o esforço para determinar se e como o filósofo atribui privilégios práticos ou ao presente, ou ao passado, ou ao futuro, ou se, alternativamente, sua posição é de neutralidade com relação a essa questão. 0 desenvolvimento da análise mostra que aqui o progresso depende criticamente do modo como Hobbes concebe a racionalidade dos comportamentos humanos. Essa ligação da racionalidade com o tempo não constitui, contudo, todo o necessário para o trabalho elucidativo a que se propõe o artigo, o qual depende ainda da consideração de vários elementos doutrinários complementares, notadamente a explicação do modo como Hobbes entende a natureza metafísica do tempo, da vida e das paixões que a animam; de sua concepção dos sinais, dos nomes e, em geral da linguagem e da relação desta com o cálculo, assim como de sua tese sobre o estatuto da felicidade humana. A partir da retomada articulada desses diferentes aspectos, o artigo concluirá mostrando que Hobbes, ao introduzir a distinção entre bem aparente e bem real, sustentará que, malgrado a shortsightness a que nos compelem as paixões, a capacidade que nos dá a razão de calcular causas e consequências nos permite visualizar prudencialmente o futuro, de modo que, podendo recurvar a linha do tempo e, assim, anular o privilégio que espontaneamente damos ao presente, não só também podemos, mas devemos, fazer do futuro o guia para construção de nossas vidas.
\end{abstract}

Palavras-chave: Hobbes; tempo; desejo; razão; cálculo.
Abstract: The aim of this paper is to assess how Hobbes conceives the link between the human desire and the divisions of time. This analytical interest shall be understood as an effort to determine whether and how the philosopher attributes practical preference either to the present, or to the past or to the future, or, alternatively, whether and how he maintains neutrality regarding these options. The development of the analysis shows that advancement in the elucidation of this point depends crucially on Hobbes' theory of the rationality of human behavior. Still, the attention to the relationship between action, rationality and time is not enough to secure a correct and global understanding of the matter, which requires the consideration of several others doctrinaire aspects of Hobbes' theory, namely (i) his metaphysical conception of time, human life and the passions which enliven it; (ii) his theory of signs, names and language and the connection of them to our capacity of calculation and, last but not least, (iii) his idea of human happiness. From the articulate survey of all these different points of Hobbesian theory the paper concludes by showing that by means of the distinction between real and apparent good, the philosopher is able to sustain that, in spite of the shortsightness of our vision caused by the force of our passions, reason not only rends us able to calculate the action of causes and effects, but provides also our capacity to anticipate at least the near future consequences of our actions. Given this rational power of prediction, human individuals may keep in control their propensity to concede priority to what is present and, correlatively, make the consideration of future a guiding device for the accomplishment of their lives.

Keywords: Hobbes; time; desire; reason; calculation. 
A questão que eu gostaria de discutir neste texto ${ }^{1}$ - sem, contudo, pretender ser exaustivo - diz respeito ao modo como Hobbes concebe a relação do desejo com o tempo, tema que, embora de uma maneira ou outra esteja presente nas leituras de sua obra, não parece ter sido tratado de maneira mais detida e focada. Quero crer que para dar início a uma tal abordagem será útil uma prospecção preliminar, de caráter geral e não exegético, sobre os modos em que pode ser concebida a relação do desejo com o tempo. Salvo melhor juízo, há quatro modos básicos de determinála, a saber:

1. atribuição de privilégio e prioridade às satisfações e benefícios presentes pelo desejo;

2. atribuição de privilégio e prioridade às satisfações e benefícios do passado pelo desejo;

3. atribuição de privilégio e prioridade às satisfações e benefícios futuros pelo desejo

e

4. neutralidade do desejo com relação à posição de satisfações e benefícios com relação às divisões usuais do tempo na série $A$, para empregar a terminologia de McTaggart (1908, p.458).

Uma maneira direta e econômica de apresentar a primeira dessas posturas encontra-se na seguinte passagem de Derek Parfit:

Considere-se a visão de que podemos racionalmente privilegiar o que nos está próximo [be biased towards the near]. Podemos racionalmente preocupar-nos menos com algum sofrimento futuro, não porque ele seja menos certo, mas simplesmente porque ele está adiante no futuro. Segundo essa visão, a racionalidade não requer um concernimento temporalmente neutro com relação ao que seja nosso interesse

1 Este texto foi primeiramente apresentado no Colóquio Internacional Hobbes: Natureza, história e política, organizado pelo GT Hobbes e promovido pelos Programas de Pós-Graduação em Filosofia da PUC-RS, da UFRGS e pelo Departamento de Filosofia da UFPEl, sob a coordenação do Prof. Marcello Vilanova, transcorrido em Porto Alegre, em novembro de 2011. Vertido ao francês, o texto foi apresentado em um Colóquio de Homenagem ao Prof. Balthazar Barbosa Filho, organizado pelo Prof. Jean-François Kervegan, que teve lugar em Paris, nas dependências da Sorbonne, no dia 12 de junho de 2012. Minha escolha de Hobbes como motivo para evocação e homenagem ao Prof. Balthazar teve como origem o seminário de leitura do Leviatã que fizemos na UNICAMP, em 1980-1981, do qual participaram, ao que lembro, os Professores Nelson Boeira, Marcos L. Müller, Carlos A. R. de Moura, Luiz R. Monzani. 
próprio. A teoria do presente-como-objetivo [P] parece ser uma visão extrema dessa visão. $\mathrm{P}$ apela apenas para os desejos presentes e sustenta que, para agir racionalmente, devemos fazer somente o que melhor satisfaça a tais desejos. $P$ parece ser, portanto, a visão que, para que sejamos racionais, devemos nos preocupar somente com nossos interesses presentes, ou com nosso bem-estar no presente momento. Chamemos esta visão de o Egoísmo do Presente. (Parfit, 1984, p.134)

A atribuição de privilégio ao passado pelo desejo, a segunda das opções apresentadas acima, dada a óbvia irreversibilidade do tempo ${ }^{2}$, não se pode constituir em uma diretriz racional para determinação das ações, embora certamente possa engendrar a postura conhecida como passadismo, como a desvalorização do presente e também como uma espécie de niilismo com relação ao futuro: a ideia de que o que tem valor, nos dá satisfação e merece nosso interesse e preocupação já aconteceu, o que o futuro nos reserva sendo apenas ou repetição ou insignificância.

A atribuição de privilégio ao futuro, que nas circunstâncias históricas contemporâneas talvez pudéssemos apelidar de posição chinesa, certamente pode vir a constituir uma diretriz de racionalidade para a ação. Neste caso a apreciação dos sacrifícios e benefícios envolvidos e acarretados por nossas decisões e ações enviesa-se em favor do mais remoto contra o mais próximo, a ideia básica sendo a de que os sacrifícios e ônus presentes serão mais do que compensados pelos confortos e bônus futuros. Supõe-se, aqui, claro, uma métrica capaz de estabelecer equivalências intertemporais entre sacrifícios e ônus e satisfações e bônus, o que então permite sustentar, a admitir-se tal posição, que para quantidades materialmente iguais dessas utilidades e desutilidades, as supervenientes no futuro terão um acréscimo do valor estimado por se colocarem no porvir. Eu me atreveria a dizer que essa é uma posição encontrável com frequência, embora implicitamente, na venda e na compra de seguros, ainda que a justificativa assumida se refira unicamente ao risco, aspecto aqui desconsiderado.

Por fim, a quarta maneira de conceber a relação do desejo com o tempo sustenta que o modo mais racional de determinar nossas opções deve posicionar-se neutralmente com relação às divisões temporais. Neste caso postula-se que a posição temporal de utilidades e desutilidades não lhes altera o valor estimado, o acontecido, o que acontece e o que está por acontecer dispensando, ceteris paribus e, conforme o caso, satisfações ou sacrifícios de valor equivalente, independentemente da posição temporal em que se encontrem.

2 Hobbes diz a propósito deste ponto: "é impossível haver deliberação quanto às coisas passadas, pois é manifestamente impossível que estas sejam mudadas" (Hobbes, 1974, p.41). Nas demais citações do Leviatã, as referências à edição de Molesworth serão feitas mediante a inserção, entre parênteses, do número da página dessa edição que corresponda ao texto citado segundo a edição da Editora Abril. 
Agora bem, será possível situar a Hobbes com relação a esse quadro de alternativas abstratas? E, se a resposta puder ser positiva, como e em que termos se poderá fazê-lo? Para dar resposta a estas indagações, o procedimento mais promissor parece-me ser o de tentar mapear o modo como as condições temporais são introduzidas por Hobbes ao longo de sua análise da natureza humana, da condição natural dos homens e de sua teoria sobre a saída do estado de natureza e instituição do Estado.

Contudo, desde logo se pode dizer que a atribuição de privilégio ao passado é uma posição que pode ser excluída liminarmente da análise a ser feita, tanto porque, conforme dito acima, esta não pode vir a ser propriamente uma diretriz de ação, quanto porque não parece haver nas análises hobbesianas qualquer traço de valorização de tempos passados, nenhuma nostalgia de retorno a uma situação original presuntivamente idílica.

À primeira vista, também parece dever ser desconsiderada in limine a posição privilegiadora do presente, uma vez que, como observa acertadamente Kavka, dentre a características da natureza humana destacadas por Hobbes encontra-se a forwardlookingness (cf. Kavka, 1986, p.33), uma constitutiva preocupação com as condições de vida futuras, a qual é tida como um requisito necessário da racionalidade de nossas condutas.

No entanto, como Hobbes também diz que "não podemos descartar este apetite irracional que nos faz gananciosamente preferir ao bem futuro um bem presente" (Hobbes, 1992, p.81), este ponto revela-se mais problemático do que parece inicialmente. Jean Hampton apresenta esta dificuldade observando: "se eu desejo viver o momento, como estarei errado e procedendo irracionalmente ao fazêlo, dado que, de acordo com Hobbes, o que é bom para mim é o que eu desejo?" (Hampton, 1986, p.82).

Evidentemente, como expressamente afirmado na passagem citada do De cive, a posição de Hobbes com relação a este ponto é que tais condutas, ainda que encontradiças, são irracionais. 0 ponto de Hampton, contudo, está em exigir que se justifique essa alegação de irracionalidade, tendo em vista os termos da análise hobbesiana da condição natural, os quais, pelo menos em um exame perfunctório, não parecem permitir a exclusão da preferência pelo presente pelos indivíduos que se encontrarem sob tal condição. Convém, portanto, examinar este ponto com mais atenção. 
Antes de fazê-lo, antes de examinar como se coloca a questão do tempo na ótica da orientação dos comportamentos no estado de natureza, convém, contudo, considerar o que talvez se possa denominar de análise metafísica do tempo feita por Hobbes. No capítulo III do Leviatã, Hobbes diz:

Só o presente tem existência na natureza; as coisas passadas têm existência somente na memória, mas coisas que estão por vir não têm existência alguma, sendo o futuro apenas uma ficção do espírito, aplicando as consequências das ações passadas às ações que são presentes, o que é feito com muita certeza por aquele que tem mais experiência, mas não com certeza suficiente. (Leviatã, p.22 (15))

No De corpore, lê-se:

Também a palavra "futuro" é um nome, mas uma coisa futura ainda não é, e tampouco sabemos, quando falamos do futuro, se o futuro algum dia será. Entretanto, como estamos acostumados a enlaçar pelo pensamento o que é passado ao que é presente, significamos esse laço com o nome futuro. (Hobbes, 2009, Cap. II, 6, p.45) ${ }^{3}$

A fixar-se fiadamente nestes textos, o leitor será naturalmente tentado a pensar que, para Hobbes, há uma predominância absoluta do presente, seja em nossa cognição, seja em nossas preferências, pois, pelo menos à primeira vista, não se vê como o que não existe possa ser objeto de cognição e desejo. Confirmada essa impressão, seguir-se-ia que nosso horizonte de conhecimento e preocupações seria sempre próximo, inviabilizando tanto as grandes recordações e o estoque de lições que a vida pretérita traz consigo, quanto o aprofundamento das antecipações, o cuidado com o porvir e formas mais ou menos elaboradas de prudência e planejamento. ${ }^{4} \mathrm{E}$ correlatamente poder-se-ia dizer que a importância cognitiva e a relevância afetiva dos objetos da experiência seriam igualmente sempre evanescentes.

Contudo, a posição de Hobbes não é essa. Nas mesmas análises do De corpore de onde extraímos a passagem recém-citada, o filósofo esclarece que podemos nomear até mesmo o impossível e que nomear ao nada, ademais da utilidade evidente como quando, segundo seu exemplo, tiramos 2 e depois 3 de 5 e dizemos que restou nada-, também nos permite, para efeitos de raciocínio, considerá-lo como uma coisa (cf. De corpore, pp.45-47). É de concluir-se, portanto, que Hobbes separa, como é

3 As citações desta obra serão feitas pela reprodução do título latino (De corpore) seguido da indicação da página desta edição e tradução brasileiras.

4 É o que sugere a passagem seguinte: "E quando qualquer objeto é afastado dos nossos olhos, muito embora permaneça a impressão que fez em nós, outros objetos mais presentes sucedem-se e atuam em nós, e a imaginação do passado fica obscurecida e enfraquecida, tal como a voz de um homem no ruído diário. Daqui se segue que quanto mais tempo decorrer desde a visão ou sensação de qualquer objeto, tanto mais fraca é a imaginação. Pois a contínua mudança do corpo do homem destrói com o tempo as partes que foram agitadas na sensação, de tal modo que a distância no tempo e no espaço têm ambas o mesmo efeito em nós" (Leviatã, p.16). 
forçoso, ontologia e semântica e autonomiza o significado, admitindo, para usar sua expressão, que por razões especulativas (idem,II, 6, p.4), nos ocupemos, teórica e praticamente, também com o que não existe.

Estabelecido esse ponto básico e geral, o passo seguinte está em ver de que modo tais razões especulativas nos permitem levar em conta o tipo específico de inexistente que é o futuro, o qual, nomeado pela palavra "futuro" ${ }^{5}$, não é, contudo, mais do que "uma ficção do espírito" (Leviatã, p.22 (15)). Creio que se pode dizer que Hobbes modula essa autorização para tratar do futuro em dois regimes: um estrito, narrow, e um ampliado, broad, para tomar de empréstimo os termos usados pelas análises contemporâneas dos conteúdos mentais. No sentido estrito, o conhecimento do futuro restringe-se àquilo que o agente pode fazer por si mesmo, o que, embora possível também para os homens ${ }^{6}$, de modo absoluto, só pode ser admitido de Deus. É o que nos explica o texto seguinte: "a previsão das coisas que estão para vir, que é providência, só compete àquele por cuja vontade as coisas devem acontecer. Dele apenas, e sobrenaturalmente, deriva a profecia" (idem, ibidem).

No sentido amplo, porém, nossa capacidade de pensarmos sobre o futuro e de podermos, por conseguinte, introduzi-lo como uma referência para orientação de nossas deliberações e condutas se amplia consideravelmente. Com efeito, nos textos que estamos a considerar, Hobbes distingue essa capacidade de prever [foresight] as coisas que estão por vir, e que, como dito, se encontra na alçada somente daquele por cuja vontade as coisas devem acontecer, da presunção do futuro, esta última da competência do prudente, isto é, daquele que, por experiência, sabe como associar consequências a certos antecedentes. 0 exercício desta competência, esclarece ainda Hobbes, depende do conhecimento de algo a que o filósofo dá o nome de sinais, cujo caráter depende de que o observador tome certas linhas de continuidade e subordinação de eventos observadas anteriormente como um padrão cuja repetição é presumida provável em circunstâncias análogas.

Releva observar, porém, que a capacidade de reconhecer sinais, definidora do prudente, não deve ser vista como prerrogativa exclusivamente humana, pois Hobbes diz expressamente que também os animais a podem possuir. ${ }^{7}$ Esta anotação exige, contudo, esclarecimentos adicionais, pois, em vista de que Hobbes distingue sinais naturais e arbitrários (cf. De corpore, p.41), convém sublinhar que estes últimos

\footnotetext{
5 Lê-se, no De corpore: "também a palavra futuro é um nome, mas uma coisa futura ainda não é, e tampouco sabemos, quando falamos do futuro, se o futuro algum dia será" (De corpore, p.45).

6 Hobbes diz, por exemplo: "assim pois, é ciência o tema do qual sabemos verdadeiro algum teorema, seja por conhecimento das causas, seja por geração do assunto derivada do raciocínio correto. (...) por demonstração a priori somente é facultada aos homens a ciência daquilo cuja geração depende do arbítrio deles" (Hobbes, 1845, p.92).

7 Diz o texto a que aludimos: "contudo, não é a prudência que distingue o homem dos outros animais. Há animais que com um ano observam mais e alcançam aquilo que é bom para eles de uma maneira mais prudente do que jamais alguma criança poderia fazer com dez anos” (Leviatã, p.22 (16)).
} 
estão para além da capacidade animal e que, dentre eles, ainda mais distanciados estão os nomes, especialmente quando articulados discursivamente ${ }^{8}$, ponto que, aliás, é de grande relevância para a elucidação do modo como Hobbes concebe nossa relação com o tempo.

Com efeito, no capítulo II do De corpore, ao tratar dos vocábulos, Hobbes diz que para que possamos superar o caráter inconstante e efêmero de nossos pensamentos, isto é, para que possamos efetivamente pensar, nos são indispensáveis sensibilia monimenta, denominados notae - termo vertido pelas professoras Maria Isabel Limongi e Viviane de Castilho Moreira, como marcas - os quais, como as amostras de cores ou os numerais, são os instrumentos sem os quais, pelo menos para nós homens, os registros de experiência se tornam instáveis e rapidamente caducos. Mais importantemente ainda, graças aos nomes podemos descolar nossa experiência da idiotia do singular, eis que eles nos facultam formar, a partir de experiências particulares, regras universais. Hobbes apresenta este ponto por meio da análise seguinte:

aquele que tem o uso das palavras quando considera tal igualdade [a dos ângulos de triângulos de diferentes formatos], quando observa que ela é consequência, não do comprimento dos lados, nem de qualquer outro aspecto particular do triângulo, mas apenas do fato de os lados serem retos e os ângulos três, e de ser isso o que o levava a denominar tal figura um triângulo, não hesitará em concluir universalmente que tal igualdade dos ângulos existe em todos os triângulos, sejam eles quais forem, e em registrar sua invenção nestes termos gerais: "todo triângulo tem seus três ângulos iguais a dois ângulos retos”. (Leviatã, p.26 (22))

Fica esclarecido assim porque a "imposição de nomes", ao transformar "o cálculo das consequências de coisas imaginadas num cálculo das consequências de apelações" (Leviatã p. 26 (22)), alarga sobremaneira o espectro de nossa compreensão das coisas e também - como nos interessa especialmente no presente contexto -, segundo precisa ainda Hobbes, "libera nosso cálculo mental do espaço e do tempo" (Hobbes, 1974, p. 26 (22)). ${ }^{9}$

Ora, é evidente que esta possibilidade de transcendermos o confinamento espacial e temporal de nossas experiências e de calcularmos as relações entre as coisas de maneira geral não apenas permite que ampliemos o espectro dos signos

8 No capítulo VIII dos Elements of Law, lemos: "o homem, no discernimento de suas faculdades, abandona toda comunidade de animais graças à sua faculdade de atribuir nomes" (Hobbes, 2002, p.65). No Capítulo X, 1 do De homine, Hobbes diz: "a fala ou linguagem é a conexão dos nomes constituída pelo arbítrio dos homens para significarem as séries de concepções das coisas sobre as quais pensamos. Assim como está o nome pela ideia ou conceito de uma coisa, assim também está a fala para o discurso da mente. E isso parece ser próprio do homem. Pois embora alguns animais ensinados apreendam o que queremos e ordenamos por meio de palavras, eles não o fazem por meio das palavras enquanto palavras, mas enquanto signos, pois eles desconhecem o significado das coisas constituído pelo arbítrio humano" (Hobbes, 1845, p.88).

9 Tradução ligeiramente alterada, com a substituição de 'alivia', por 'libera' como versão de 'discharges'. 
de que nos podemos valer para extensão e progresso de nossos conhecimentos, mas nos faculta também, graças a isso, o alargamento de nosso descortino do mundo e de nossa capacidade de prospecção e antecipação do futuro. No entanto, como Hobbes não deixa de alertar, neste último caso, tendo em vista "a dificuldade de observar todas as circunstâncias" (Leviatã, p.22 (15)), a verdadeira sabedoria, a ciência que nos leva além da prudência é rara. Além disso, enquanto saber baseado e derivado das relações entre nomes universais, esse conhecimento é um conhecimento de regularidades, um conhecimento nomológico, se assim podemos dizer, não o conhecimento de futuros contingentes, como são os fatos decorrentes das iniciativas humanas. De outra parte, porém, é preciso não esquecer que na medida em que o desenho do futuro depende da vontade dos homens, isto é, na medida em que está em nosso poder pelo menos configurar as condições gerais de nosso convívio e levá-las a cabo, nos é facultado, senão a scientia no sentido estrito da palavra, pelo menos o conhecimento [cognitio], que é o nome a ser dado ao conhecimento dos fatos, conforme a lição do parágrafo 4 do capítulo 10 do De homine referida acima. ${ }^{10}$

Se voltarmos agora às variantes de posicionamento com relação ao tempo que distinguimos inicialmente torna-se claro que, bem consideradas as coisas, a análise metafísica - como acima sugerimos denominá-la - e epistemológica do tempo feita por Hobbes obviamente não nos confina ao presente, mas antes abre espaço para uma antevisão do futuro, ainda que limitada.

No entanto, esse reconhecimento de que o caráter fugaz e evanescente de nosso pensamento pode ser contornado e que somos capazes de associar estavelmente antecedentes a consequentes, se nos permite dizer que o futuro não é do ponto de vista epistêmico absolutamente inacessível, ainda nada nos diz sobre o modo como nosso desejo se posiciona com relação às estases temporais, para desta ver fazer empréstimo a Heidegger. ${ }^{11} \mathrm{O}$ que é também dizer que para avançarmos nestas notas é preciso que passemos a examinar como Hobbes analisa o papel do tempo na determinação de nossas deliberações e condutas, sem o que não há como voltarmos produtivamente às questões de que partimos.

\section{4}

Quando passamos à consideração do modo como Hobbes analisa o que denomina de movimentos voluntários, isto é, quando passamos ao que um tanto anacronicamente podemos denominar de terreno prático, ou, para empregarmos referências hobbesianas, nos deslocamos para o domínio dos predicamentos da

10 Lê-se ali: "Quando vero de veritate facti agitur, non propre scientia, sed simpliciter cognitio dicitur" (Hobbes, 1845, p. 92).

11 Cf. Heidegger, 2012, p.895. (p.329 da edição Max Niemeyer, Tubingen, 1927). 
qualidade e da relação, apresentados nas tábuas do De corpore, o primeiro registro a fazer é que "a imaginação é a origem interna de todos os movimentos voluntários" (Leviatã, p.36 (38)), de sorte que, muito embora antes destes últimos já ocorram pequenos movimentos no interior de nosso corpo que estão na origem de nossos apetites e desejos, a verdade é que quando nos deslocamos para o plano das condutas humanas a forma assumida pelos objetos destas últimas - seu caráter de bons ou maus $^{12}$ - depende primeiramente da imaginação. É por isso que Hobbes também diz que "apetites e aversões são suscitados pela previsão das boas ou más consequências e sequelas da ação sobre a qual se delibera" (idem, p.42 (50)).

Oakeshott analisa e esclarece esplendidamente este ponto ao dizer:

Um animal (...) pode sentir prazer e dor, mas seus movimentos vitais são afetados somente pelo ambiente com o qual ele se encontra em contato imediato; seus apetites e aversões são posicionamentos de gostar ou desgostar somente em relação àquilo que está presente e sua fome é a fome do momento. Já os seres humanos possuem dotes que ampliam o espectro de seus apetites e aversões, dos quais os principais são a memória e a imaginação. Os seres humanos são capazes de estocarem suas experiências de prazer e sofrimento e lembrarem de suas causas posteriormente. Além disso, demais dos objetos que se encontram em seu inescapável ambiente, rodeiam-se eles de um mundo de experiências imaginadas e são capazes de desejar o que não está presente senão na imaginação. (Oakeshot, 1991, p.300 - cf. Leviatã, cap.XII, p.69 (94))

À pertinência desse comentário de Oakeshott, convém acrescentar ainda o registro - como ele próprio, aliás, não deixará de fazê-lo logo adiante - de que a profundidade desses movimentos antecipatórios típicos do desejo humano, assim como a importância crucial que precisamos atribuir às predições associadas a nossa busca de satisfação e elisão de sofrimentos, só aparecem com toda clareza quando damos o destaque devido ao caráter constitutivamente dinâmico de nossos desejos e afetos. Este é o ponto que Hobbes estabelece da maneira mais clara e formal possível na declaração famosa do capítulo XI do Leviatã:

A felicidade é um contínuo progresso do desejo, de um objeto para outro, não sendo a obtenção do primeiro outra coisa senão o caminho para conseguir o segundo. Sendo a causa disso que o objeto do desejo do homem não é gozar apenas uma vez, e só por um momento, mas garantir para sempre os caminhos de seu desejo futuro. (Leviatã, p.64 (85))

À luz desta lição podemos concluir, portanto, que Hobbes pelo menos iguala a valorização do futuro pelo desejo à estima que temos pelo presente, pois, sendo a vida movimento e dinâmico o desejo, já desde sempre nos vemos propelidos adiante e, portanto, a priori concernidos com o sucesso ou o malogro futuro de nossas

12 Hobbes diz: "mas seja qual for o objeto do apetite ou desejo de qualquer homem, esse objeto é aquele a que cada um chama bom; ao objeto de seu ódio e aversão chama mau, e ao de seu desprezo chama vil e indigno" (Leviatã, p.37 (41)). 
aspirações. Face à cláusula que nos diz que a obtenção do primeiro dos objetos que dão satisfação ao desejo outra coisa não é senão o caminho para conseguir o segundo, parece que se deve mesmo dizer que o sujeito hobbesiano não só é constitutivamente projetado ao porvir, mas tem a este como mais valioso do que o presente, uma vez que o sentido dos bens presentes, seu valor, é dito consistir - e consistir tão somente - na abertura de caminho para o já agora ambicionado conseguinte, isto é, na viabilização da passagem à frente, cuja base ontológica encontra-se na dinâmica interna do movimento vital. Ademais disso, este último, em vista da inexistência do finis ultimus e do summum bonum (Leviatã, p.64 (85)), precisa ser concebido como sendo constitutivamente transiente, serial e aberto.

É verdade que na sequência imediata Hobbes nos adverte para a necessidade de bem entender este ponto, pois assinala que a causa que nos faz ansiar sempre por poder e mais poder "nem sempre é que se espere um prazer mais intenso do que aquele que já se alcançou" (Leviatã, p.64 (86)), mas antes o fato de "não se poder garantir o poder e os meios para viver que atualmente se possuem sem adquirir mais ainda" (idem, ibidem).

0 que é dizer que a preferência pelo futuro funda-se menos na expectativa de prazeres maiores e mais intensos à frente do que na preocupação de ter condições para manter o fluxo dos desejos, o que é nosso maior desejo, uma vez que, ensinanos o texto:

O sucesso contínuo na obtenção daquelas coisas que de tempos a tempos os homens desejam, quer dizer, o prosperar constante, é aquilo a que os homens chamam felicidade (...); pois não existe uma perpétua tranquilidade do espírito, enquanto aqui vivemos, porque a própria vida não passa de movimento, e jamais pode haver desejo, ou medo, tal como não pode deixar de haver sensação." (Leviatã, p.43 (51))

No entanto, por profundo e sólido que seja este privilégio atribuído ao futuro, cuja base encontra-se em uma análise metafísica - ou, se se preferir, ontológica - da vida, ele não pode ser a última palavra com relação à determinação das relações do desejo humano com o tempo, pois o desejo, nele mesmo, tem o encurtamento do horizonte temporal como uma determinação constitutiva. Este é o caso, manifestamente, dos apetites cuja satisfação e deleite vinculam-se a objetos presentes (cf., Leviatã, p. 38 (42)), dos quais cabe dizer que cada manifestação, ou caso, tem como limite temporal o período necessário a sua satisfação. Mas mesmo os desejos dirigidos a e determinados por fins e consequências previstas, a que Hobbes dá o nome de paixões simples (idem, ibidem (43)) e que são o desdobramento natural e próprio do querer de seres capazes de transcenderem as limitações dos contextos imediatos e das necessidades presentes - as paixões que se ligam aos prazeres do espírito, como diz o filósofo (cf. idem, ibidem) - a despeito de que abram espaço para a consideração do futuro, não só não podem, conforme a passagem do De cive que 
citamos ao começar, "descartar este apetite irracional que nos faz gananciosamente preferir ao bem futuro um bem presente" (Do cidadão, cap.3, §32 - Hobbes, 1992, p.81), mas, frequentemente, são a causa desse encurtamento do horizonte de decisões. Este é inequivocamente o caso, por exemplo, do desespero, que Hobbes define como o apetite sem a crença de conseguir; ou da cólera, definida como a coragem súbita; ou da cobiça, entendida como desejo de riquezas; ou da ambição, cujo objeto são os cargos e a proeminência, ou a ânsia de vingança, caracterizada como o propósito de causar dano a outrem, ou o ciúme, e assim por diante.

Em vista disso, parece que a consideração adequada do futuro - isto é, segundo Hobbes, pelo menos o controle da propensão a dar prioridade ao presente -, se não pode, assim, fundar-se em estímulos que nos venham das paixões, só parece poder vir a ocorrer com auxílio da razão e de seu correto exercício, vale dizer: do cálculo pelo qual analisamos prazeres e penas em uma escala temporal longa e somando-os algebricamente encontramos conclusivamente seus respectivos valores, o que estão nos permitirá distinguir com clareza o bem aparente do bem real.

No capítulo $\mathrm{XI}$, § 5 , do De homine, Hobbes introduz esta última distinção dizendo:

Ademais, o bem (como o mal) é dividido em real e aparente. Não porque qualquer bem aparente possa não ser verdadeiramente bom em si mesmo, sem consideração de mais nada que dele se siga, mas porque em muitas coisas onde há uma parte boa e uma parte má há uma conexão entre essas partes que não pode ser quebrada. Portanto, embora em cada uma delas haja muito de bom ou muito de mal, a cadeia como um todo será em parte boa e em parte má. E sempre que a parte maior for boa dir-se-á que a série é boa e é desejada; ao contrário, se a maior parte for má e se, além disso, for reconhecida como tal, o todo será rejeitado. Daí acontece que homens inexperientes que não olham suficientemente de perto as consequências de longo prazo das coisas, aceitam o que parece ser bom, não vendo o mal anexado a ele e depois experimentando prejuízos. $E$ isto é o que é quer dizer quem distingue bem e mal como real e aparente. (Hobbes, 1972, p.48)

Todavia, ao contrário do insinuado na introdução desta citação, o que se lê na passagem não é a garantia de prevenção dos erros passionais pela razão, mas antes o registro de que o próprio exercício da razão se faz causa do encurtamento de horizontes e dos equívocos que lhe são correlatos, uma vez que o que Hobbes nos descreve no texto não é uma perturbação da visão e do juízo por força da ação de estímulos sensíveis, mas antes uma falha cognitiva; um erro ao raciocinar, como diz Hampton (1986, p.82) na análise que dedica ao que propõe denominar de shortsightedness de nossa faculdade superior, esta espécie de inevitável sujeição ao engano no cálculo do valor de bens futuros a que nos encontramos sujeitos.

De outra parte, é preciso assinalar também que, ainda que não falhasse a razão no somatório algébrico de prazeres e dores inclusos na série de consequências, nem por isso poderia ela, por si só, vir a oferecer a justificativa final e completa 
para o alegadamente necessário privilégio a ser atribuído ao futuro, pois o resultado dessas operações depende dos valores unitários a serem atribuídos aos elementos computados, aos prazeres e dores cujos valores são necessariamente fixados extra racionalmente por nossa capacidade de desejar. Este ponto é uma clara implicação da análise hobbesiana da deliberação, cuja lição positiva é que o ato de querer é determinado pelo último apetite ou aversão, e a negativa a rejeição da definição de vontade como apetite racional, eis que isso nos levaria a negar, contraintuitivamente, a existência de "atos voluntários contra a razão" (Leviatã, 1974, p.41 (48)). Apresentando este ponto em termos gerais, Warrender comenta: "tanto a razão quanto a deliberação são escravas das paixões na medida em que por si próprias elas não fornecem nenhum motivo para a ação" (Warrender, 1957, p.269 cf. Oakeshott, 1991, pp.308-309).

Ora, sendo assim, parece forçoso admitir que, na estimativa de prazeres e dores presentes e futuros, os mais próximos são espontaneamente considerados mais valiosos do que os remotos, o que, aliás, provoca disposições assimétricas do desejo, que quer as dores e penas tão distanciadas quanto possível, e os prazeres e satisfações inversamente. Uma explicação clássica deste ponto é fornecida por Alfred Marshall, o grande economista de Cambridge, que ao analisá-lo comenta:

Se as pessoas estimassem que os benefícios futuros fossem tão desejáveis como os que lhe são análogos no momento atual, provavelmente tratariam de distribuir seus prazeres e demais satisfações uniformemente em todas as etapas da vida. Estariam dispostas, consequentemente, a renunciar, como regra geral, a um prazer atual por um igual no futuro, sempre que tivessem segurança com relação a este. Mas a natureza humana está constituída de tal modo que ao estimar o valor presente de um benefício futuro, a maioria das pessoas faz, geralmente, um desconto, que aumenta com o período de tempo em que o benefício é diferido. (Marshall, 1920, p.76)

No entanto, este raciocínio no qual é impecavelmente justificada uma certa preferência pelo presente - uma preferência que não está assentada nem no papel disruptivo das paixões, nem em erros de cálculo e que, ademais disso, é corriqueiramente atestada pela existência das taxas de desconto aplicadas quando da comercialização antecipada de papéis com vencimento diferido - não pode ser aceito por Hobbes, que, como vimos, faz da valorização do futuro o sinal da racionalidade.

Sendo assim, se as paixões em vez de ocasionarem a preferência pelo futuro parecem impelir-nos antes na direção inversa, e se a razão - seja por falível, seja, muito mais decisivamente, porque constitutivamente alheia e indiferente às preferências - tampouco pode fazê-lo, parece difícil explicar o que justifica a defesa pelo filósofo da racionalidade da forwardlookingness humana, para usar a expressão de Kavka. 
A solução dessa dificuldade, o esclarecimento do que fundamenta a prioridade atribuída por Hobbes à preocupação com o futuro requer, preliminarmente, que se enfatize que ela não diz respeito à qualidade esperada do que virá, que é incerta e que o filósofo admite que poderá ser boa ou má. A seguinte passagem do capítulo 12 do Leviatã explica bem este ponto:

Pois quando se está certo de que existem causas para todas as coisas que aconteceram até agora ou no futuro virão a acontecer, é impossível a alguém que constantemente se esforça por se garantir contra os males que receia, e por obter os bens que deseja, não se encontrar em eterna preocupação com os tempos vindouros. De modo que todos os homens, sobretudo os que são extremamente previdentes, se encontram numa situação semelhante à de Prometeu. Porque tal como Prometeu (nome que quer dizer homem prudente) foi acorrentado no monte Cáucaso, um lugar de ampla perspectiva, onde uma águia se alimentava de seu fígado, devorando de dia o que tinha voltado a crescer durante a noite, assim também o homem que olha demasiado longe, preocupado com os tempos futuros, tem durante o dia seu coração ameaçado pelo medo da morte, da pobreza e de outras calamidades, e não encontra repouso nem paz para sua ansiedade a não ser no sono. (Leviatã, p.64 (85))

Vê-se assim que o privilégio atribuído por Hobbes ao futuro não tem a ver com o conteúdo bom ou mau dos acontecimentos que deverão sobrevir - cuja qualificação como portadores de uma ou outra dessas qualidades é independente de suas posições na série temporal - mas deriva do aspecto formal de nossa exposição ao tempo, do risco implicado em uma vida cujo desdobramento é constitutivamente temporal e que assim nos obriga a dizer, como Guimarães Rosa, que viver é muito perigoso.

De outra parte, não é difícil ver, portanto, que considerados os eventos neles mesmos, o caráter benéfico ou maléfico que possam ter é indiferente às divisões da série temporal, devendo-se mesmo admitir que, ceteris paribus, nada mais constando, Hobbes concordaria com a hipótese de Marshall de que as pessoas estimariam os benefícios futuros tão desejáveis como os atuais e provavelmente tratariam de distribuir seus prazeres e demais satisfações uniformemente em todas as etapas da vida, conforme dito na passagem dos Princípios de Economia citada acima.

Ocorre, porém, que essa neutralidade das partes da série temporal com relação aos eventos que sobrevém em seu interior é perturbada pela temporalização constitutiva da vida humana, que, ao prolongar-se e ao saber-se desdobrada no tempo, faz com que "o objeto do desejo do homem não [seja] gozar apenas uma vez, e só por um momento, mas garantir para sempre o seu desejo futuro” (Leviatã, p.64 (85)).

Isto quer dizer que o futuro passa a ser o mais importante para os homens, não por seu conteúdo, não pela qualidade dos eventos que trará consigo, mas por sua forma, porque ele, formalmente considerado, é idêntico à própria vida e condição de 
possibilidade de todo bem e de todo mal.

Bem entendido, essa sobrevalorização do futuro depende da e só faz sentido em vista da finitude da vida humana, ou, mais exatamente, como Hobbes costuma dizer, do medo ou do temor da morte, especialmente da morte violenta, eis que a sobrevivência, como condição de tudo mais, é o valor supremo. Por isso Hobbes diz: "as paixões que fazem os homens tender para a paz são o medo da morte, o desejo daquelas coisas que são necessárias para uma vida confortável, e a esperança de consegui-las através do trabalho" (Leviatã, p.81 (115)).

0 texto seguinte ilustra bem ainda mais fortemente a relação do temor da morte com o tempo ao dizer:

Se alguém for obrigado, pelo terror de uma morte iminente, a praticar um ato contrário à lei, fica inteiramente desculpado, porque nenhuma lei pode obrigar um homem a renunciar a sua própria preservação. Supondo que essa lei fosse obrigatória, mesmo assim o raciocínio seria o seguinte: Se não o fizer morrerei imediatamente, $e$ se o fizer morrerei mais tarde; fazendo-o, portanto, ganho tempo de vida. Consequentemente, a natureza obriga à prática do ato. (Leviatã, p.185 (288))

Vê-se assim, portanto, que o que nos obriga a pensar longe, a paixão que nos faz sábios é o temor da morte. Sua força, provém, no entanto, da temporalização constitutiva da vida, que faz do futuro a condição necessária do único remédio para um mau jogo: o dar as cartas de novo (cf. Leviatã, p.65 (87)), e que é também, nesta medida, o fundamento último de toda esperança.

Cabe, pois, dizer que a paixão que comanda toda a vida humana é o medo da morte, a paixão mais básica, mais elementar, mas colada na condição ontológica dos seres humanos e que nos faz descortinar não o caminho da vida autêntica e da decisão resoluta, como leciona Heidegger, mas o caminho da sabedoria, da moderação e de toda expectativa do melhor. É importante notar, todavia, que ela só poderá fazêlo, só poderá cumprir esse papel educador, se prevenido o deslize e a entrega à superstição, isto é, se o trabalho da razão tiver sucesso em manter o temor da morte dentro dos limites de um sadio realismo, vale dizer: se o progresso da ciência superar a ignorância das causas segundas, se impedir a aceitação de coisas acidentais como prognósticos e se, assim, vier a desmoralizar a crença nos fantasmas e deixar sem base a devoção pelo que se teme (cf. Leviatã, p.71 (98))..$^{13}$

Voltando agora às opções abstratas com que abrimos as presentes notas, percebe-se que é inequívoco, assim, que a posição de Hobbes é de privilegiar o futuro, de considerar que é a ele que nosso desejo deve endereçar-se, mas isso

13 Devo e agradeço à Professora Yara Frateschi a oportuna e fina advertência - feita no debate que tivemos quando da apresentação de uma primeira versão deste texto no /l Colóquio Internacional Hobbes: Natureza, história e política, realizado em Porto Alegre, nas dependências da Pontifícia Universidade Católica do Rio Grande do Sul, nos dias 9, 10 e 11 de novembro de 2011 - para a necessidade de ressaltar o papel da razão na crítica às superstições e na limitação dos efeitos do temor da morte à vida terrena, sob pena de distorção do pensamento hobbesiano. 
não pelas razões da posição chinesa, pela crença de que os prazeres e benefícios futuros valem mais do que os presentes, mas, na verdade, por uma ordem de razões totalmente diferente: pelo reconhecimento de que, sendo a vida movimento, preservá-la é o maior valor, assim como o temor da morte é a paixão mais forte, pois daquela depende a possibilidade “do sucesso contínuo na obtenção daquelas coisas que de tempos a tempos os homens desejam, quer dizer o prosperar constante (...) a que os homens chamam felicidade" (Leviatã, p.43 (51)).

É por isso que - dada a vida e, como se acaba de ver, admitido que a felicidade é um contínuo progresso do desejo, de um objeto para outro - o temor da morte tem força para recurvar a linha do tempo, para anular a preferência pelo presente e para tornar o interesse pelo futuro o princípio determinante de nossa existência. Este princípio, como importa sobremodo ao filósofo político que é Hobbes, abre espaço, como bem sabemos, para a observância da primeira e fundamental lei da natureza, a que nos diz que enquanto não houver para nenhum homem a segurança de viver todo o tempo que geralmente a vida permite aos homens viver: "é um preceito geral da razão (...) que todo homem deve procurar a paz e segui-la” (Leviatã, p.82 (117)).

\section{Referências:}

\section{Obras de Hobbes}

Hobbes, T. (1839-1845). The English Works of Thomas Hobbes of Malbesbury, vol. 3. Molesworth, W. (ed.). London.

- (1845). Thomas Malmesburiensis opera philosophica quae Latine scripsit omina, vol. II. Molesworth, W. (ed.). London.

. (1996). Leviathan. Tuck, R. (ed.). Revised Student Edition. New York: Cambridge University Press.

(1972). Man and Citizen. Gert, B. (ed.). New York: Anchor Books, Doubleday \& Company, Inc.

- (1974). Leviatã. Tradução de João Paulo Monteiro e Maria Beatriz Nizza da Silva. São Paulo: Abril Cultural.

Martins Fontes.

- (1992). Do cidadão. Tradução de Renato Janine Ribeiro. São Paulo:

- (2002). Os elementos da lei natural e política. Tradução de Fernando

Dias Andrade. São Paulo: Ícone Editora.

- (2009). Do corpo - Parte I, Cálculo ou Lógica. Edição em latim e português. Tradução e notas de Maria Isabel Limongi e Vivianne de Castilho Moreira. Campinas: Editora Unicamp. 


\section{Outras obras}

Hampton, J. (1986). Hobbes and the Social Contract Tradition. New York: Cambridge University Press.

Heidegger, M. (2012). Ser e Tempo. Tradução de Fausto Castilho. Petrópolis, RJ e Campinas, SP: Vozes e Editora da Unicamp

Kavka, G. (1986). Hobbesian Moral. and Political Theory. Princeton New Jersey: Princeton University Press.

McTaggart, E. (1908). The Unreality of Time, Mind, New Series, 17(68).

Marshall, A. (1920). Princípios de Economia, Livro III, cap. V, § 3. [E-book versão online oferecida pelo Liberty Fund (The Online Library of Liberty), baseada na $8^{\mathrm{a}}$ edição da obra, publicada por Macmillan \& Co., em 1920]. Recuperado de: http://files.libertyfund.org/files/1676/Marshall_0197_EBk_v6.0.pdf. Acesso em: 04.05.2016.

Oakeshot, M. (1991). The moral life in the Writings of Thomas Hobbes, in Rationalism in politics and other essays. Indianapolis: Liberty Fund.

Parfit, D. (1984). Reasons and Persons. Oxford, UK: Oxford University Press.

Warrender, H. (1957). The Political Philosophy of Hobbes. Oxford, UK: Oxford University Press.

Recebido em: 10.09.2015

Aceito em: 01.04.2016 